\title{
Participatory archiving
}

The next generation in archival methodology

A rchives and archivists have generally shied away from accepting all-digital donations. Possibly because of our general aversion to all-photocopy collections, archivists have traditionally turned down all-digital collections because they are not the genuine article. There are, of course, acceptations to the rule-for example, if the items or images were so rare or of high research value that a digital donation was the only way that they could be added to the collection. But, digital donations open up a can of worms that archivist would rather avoid.

That said, digital donations, and the issues surrounding them, are going to become more prevalent as community or participatory archiving becomes more common. Popularized by the Mass. (Massachusetts) Memories Road Show, community archives and archiving entrusts the members of a community, or those with a shared experience, to create and describe their particular collections. And in doing so, they are encouraged to offer up their photographs, scrapbooks, ephemera, and other memorabilia for digitization and inclusion in the repository as all-digital collections.

In this community archiving formula, participants are not asked to donate their materials, but only to donate their digital surrogates. This involvement can be random, but it appears that the projects get the best response when the participation is scheduled as routine programming that brings community members to the institution for a daylong event. In this type of participatory communal archiving, the citizens of the area are the ones charged with documenting and describing their own communities, the archivists serve as the facilitators, and the institution or repository serves as the archives or virtual archives for the digital collection.

Using this formula, Mass. Memories Road Show personnel, based at UMass Boston, scheduled events across the state, where they invited residents to come in to help document their communities or localities by permitting the staff to digitize their photographs and other materials for inclusion in the all-digital collection. The programming for these events might include a speaker or a panel discussion on the community or topic that is being covered. ${ }^{1}$ This form of engagement is gaining so much traction that last summer the National Endowment for the Humanities established the "Common Heritage" grant program to better document and create these types of virtual community repositories. ${ }^{2}$

\section{Challenges and possible solutions}

One of the reasons that archives and archivists have shied away from purely digital collections and donations is because of the various storage and preservation problems that they present. Mainly, with a digital collection, what exactly is being stored and

Eddie Woodward is senior local records archivist at the Library of Virginia, email: eddie.woodward@lva. virginia.gov

(C) 2016 Eddie Woodward 
preserved? And then there are all of the digital preservation issues associated with electronic records. Does the receiving repository have a digital preservation strategy in place? What happens when there is not actual physical backup, master, or security copy, and the only thing that you have is the digital substitution? One simple solution might be to print out a hard copy of the digital photograph.

Because of the fragility of technology, and the fact that technology can fail, Doug Nishimura, senior research scientist at the Image Permanence Institute recommends that photographs be printed out for security's sake. In this scenario, a printed copy of the photograph serves as the master security "file,"and might replace or at least supplement the uncompressed TIF archival master (wherever or however you chose to store it). ${ }^{3}$

Other headaches for all-digital donations include deeds of gift and copyright issues. If ownership of the original negative or print photograph are not transferred to your institution, then what is? This could become particularly problematic when one repository receives a digital donation and another repository winds up with the actual items.

One solution is to have the copyright of the image itself, and not necessarily the physical photograph, transferred to the receiving repository. However, this is impractical for a number of reasons. A more acceptable agreement would permit the receiving repository to have perpetual, nonexclusive rights to use the image however it sees fit. And then, the actual physical items could be donated anywhere, without affecting the status of the original all-digital deed of gift. Use of the digital images for anything other than educational or personal purposes would need to be cleared by the copyright holder.

As challenging as all of this may appear, there is real value in building collections in this way. First and foremost, the receiving repository is coming into possession and making accessible items that it would probably not have if it did not agree to a digital donation. Plainly put, many people with materials of high research value are not willing to let them go. And if the only way they might be accessible to researchers is via donation, many potential donors might never even make you aware of their existence. However, once they are aware of the digital option, you might begin to see them coming out of the woodwork. Again, this type of communal archiving, centered around a community or shared experience, could build a comprehensive collection of materials, especially when participants understand that they are not giving up their prized possessions. The donors are the experts on their own collections and can provide the quality descriptive metadata needed (and desired) to make the materials accessible in an online environment. Additionally, generally speaking, people like to see their names in print and their stuff online, and this could provide added incentive to their participation in the community archiving project. ${ }^{4}$

Next to the high research value is the opportunity for the positive community outreach and engagement. History, heritage, and tradition sells and this type of scenario might give those who weren't really interested in sharing their collection, an opportunity to become involved in an ongoing project at the repository. These types of projects might bring people into your library who might have never had a reason to come in otherwise. And once they become involved in telling their story, they often become invested, frequently taking on a sense of ownership in the project. Your repository's development officers are always looking for ways to engage the passions of their patrons. This way, the patrons can become involved without having to sacrifice their stuff. In this scenario, everybody wins.

Obviously, we are still in the early days for community or participatory archiving, and no one can predict if it really could become the next phase in archival methodology. But, it does present an opportunity to build and deepen collections, especially local history collections, while offering positive outreach and engagement potential.

(continues on page 406) 
of further engaging the research community, maintaining public input, and consideration of a fee-based system.

Unavailable to speak in person, Daniel R. Shanahan's (BioMed Central) audio presentation addressed key issues related to semantic linking of data with articles. Building from a core question, "Can we trust the published literature?," Shanahan took the perspective that the questions asked, and the processes used, are the core values of research, not necessarily the outcome. One then begins to evaluate research by methods used-to do this, one needs access to the data. CrossRef and other technologies in the OpenTrials project support this new linkage model.

Holly Miller (Florida Institute of Technology), a former biochemist, discussed how new interdisciplinary, complex research paradigms are dependent on shared data. Such research is used secondarily in economics, history, and science-based legislative processes._Michael Leach, Cabot Library, Harvard University, mrleach@fas.harvard.edu

\section{Taking our seat at the table}

The University Libraries Section program, "Taking Our Seat at the Table: How Academic Librarians Can Help Shape the Future of Higher Education," focused on positive approaches academic libraries are taking to impact their communities outside traditional boundaries. Maria Martinez-Cosio (University of Texas-Arlington), led with highlights of a grant-funded collaboration in which areas of the library were turned into an after-hours academic plaza containing advising, tutoring, and group study rooms. This project, based on student need, has been very well received.

Monica Metz-Wiseman (University of South Florida [USF] Libraries) spoke about the libraries' leadership in strengthening open electronic resources, particularly textbooks, at USF. Touching on the difficult financial situation that many students find themselves in, Metz-Wiseman covered several different OER initiatives the libraries have developed that have saved USF students more than $\$ 1$ million to date.

Sue Ryan (Stetson University) presented her library's efforts to enhance the university curricula by promoting their 3-D printing lab. Ryan discussed ways in which faculty have incorporated 3-D printing into their assignments with resultant increases in student learning, as well as the wealth of presentations and publications faculty have produced as a result of their collaboration with the library.

Rounding out the panel, Catherine MurrayRust (Georgia Institute of Technology) urged librarians to involve themselves on their campuses by becoming contributors and influencers. She listed ideas for involvement and said, "If this sounds like dating advice, some of the same principles apply." Murray-Rust concluded that librarians need to develop a strategy and be intentional about putting themselves forward in order to be seen as professionals who can contribute outside traditional library boundaries.-Anne Marie Casey, Embry-Riddle Aeronautical University, caseya3@erau.edu $\mathbf{n}$

("Participatory archiving," continues from page 379)

\section{Notes}

1. "Mass. Memories Road Show," accessed March 25, 2016, http://openarchives. umb.edu/cdm/landingpage/collection/ p15774coll6.

2. "Common Heritage," National Endowment for the Humanities, accessed March 25, 2016, www.neh.gov/grants/preservation/ common-heritage.

3. Tamara Chuang, "Mailbag: Best Way to Archive Old Photos? An Expert has a Surprising Suggestion," The Denver Post, March 16, 2015, accessed March 25, 2016, www. denverpost.com/business/ci_27707891/bestway-archive-old-photos-an-expert-has.

4. Obviously, a participating repository would need a digital asset management system (DAMS) to make the collections available

(continues on page 410) 
- Confirmed the virtual vote approving the New Roles and Changing Landscapes division-level committee.

- Confirmed the virtual vote approving the Status of Academic Librarians Standards and Guidelines Review Task Force.

- Approved the name change of the Law and Political Science Section (LPSS) to the Politics, Policy and International Relations (PPIR) Section.
- Approved the renewal of the Library and Information Science (LIS) Education Interest Group.

- Approved the renewal of the Technical Services Interest Group.

- Approved the renewal of the Numeric and Geospatial Data Services in Academic Libraries Interest Group.

- Established the Contemplative Pedagogy Interest Group. $\boldsymbol{n}$

\section{ACRL Policy Statement on Open Access to Scholarship by Academic Librarians, approved by the ACRL Board of Directors during the ALA Annual Conference, June 2016}

Scholarship by academic librarians advances the fields of library and information science, influences practices of aligned professions, and informs effective advocacy. In support of broad and timely dissemination of library and information science scholarship, the Association of College and Research Libraries (ACRL) encourages academic librarians to publish in open access journals. When academic librarians choose to publish in subscription-based journals, ACRL recommends a standard practice of depositing the final accepted manuscript in a repository to make that version openly accessible.The author should be responsible for determining at what date the deposited manuscript becomes openly accessible, taking into account applicable institutional or funder policies, as well as other relevant considerations.

ACRL further encourages academic librarians to make other forms of scholarship, such as monographs, presentations, grey literature, and data, openly accessible.

It is also imperative that publishers of library and information science scholarship explore and implement publishing models to make their content openly accessible as soon as possible. Librarians who are editors, reviewers, and authors should assist with this effort by engaging with their publishers about these models.

("Participatory archiving," continues from page 406)

online. If the institution does not have a online platform, and if it is an OCLC member, it would have access to CONTENTdm's "quick start," which is included in the library's subscription at no additional charge. This trial version of the popular DAMS permits the repository to store and manage up to 100 digital records, all hosted by OCLC. Once the repository's digital presence is established, it could then promote it to the community for its positive outreach benefits, and if successful, expand the subscription so as to up the storage capacity and item count in the database. As an added benefit, these digital or virtual collections requiring no physical storage space in the library.

For more on CONTENTdm "quick start," visit their website, accessed March 26, 2016, https://www.oclc.org/contentdm/quickstart. en.html. $\boldsymbol{n}$ 